\title{
Leer, un rapto del alma
}

\section{Reading, a rapture of the soul}

\section{Fernando Bárcena*}

Recibido: 2 de junio de 2021 Aceptado: 3 de junio de 2021 Publicado: 27 de julio de 2021

To cite this article: Bárcena, F. (2021). Leer, un rapto del alma. Márgenes, Revista de Educación de la Universidad de Málaga,

2 (2), 143-149

DOI: http://dx.doi.org/10.24310/mgnmar.v2i2.12829

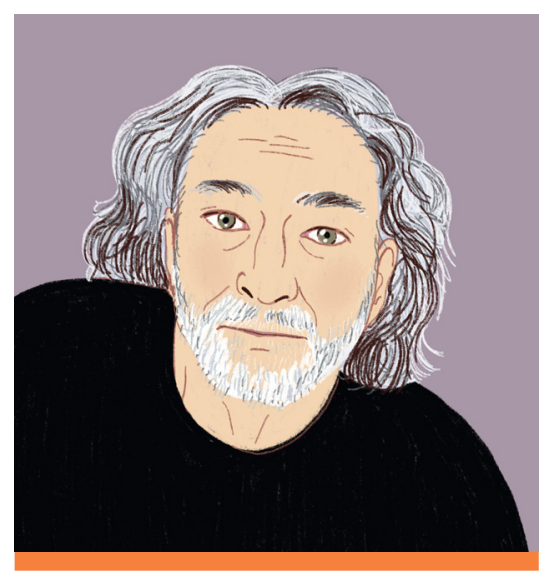

Fernando Bárcena

\section{RESUMEN}

Leer es la posibilidad de caer en la cuenta, un rapto del alma. En lo leído nos proyectamos y, a menudo, recreamos en nosotros lo que los héroes o heroínas de las novelas que más amamos viven o padecen. No se puede querer leer y pretender, al mismo tiempo, estar asegurado: es mejor no leer entonces. El lector, secuestrado por el libro, desaparece en las páginas que lee. Muchas cosas acontecen ahí. La lectura es contemplación, y supone dejar el mundo a distancia: es una inevitable ausencia de mundo y una inquieta soledad.

Palabras clave: lectura; estudio; escritura

\section{ABSTRACT}

Reading is the possibility of becoming aware, a rapture of the soul. In what we read we project ourselves and often recreate in ourselves what the heroes or heroines of the novels we love most live or suffer. One cannot want to read and at the same time claim to be insured: it is better not to read at all. The reader, kidnapped by the book, disappears into the pages he or she reads. Many things happen there. Reading is contemplation, and implies leaving the world at a distance: it is an inevitable absence of the world and a restless solitude.

Keywords: reading; study; writing

Hace algunos años, en uno de mis habituales matinales paseos por las calles de la ciudad donde vivo, me adentré en una librería y, ojeando libros aquí y allá, me encontré con el ensayo cuyo título, La vocation, escrito por Judith Schlanger, me atrajo de inmediato. Me gusta, cuando compro un libro, leer sus primeras y últimas líneas, como si fuese una partitura. Así que leo el incipit del libro, que me mueve a adquirirlo: «Comme vivre et 
faire de ma vie? La forme moderne que prend cette question de toujours est la vocation. La vie me réalise à travers une activité à laquelle je m'identifie».

La pregunta relativa a esa vocación de la que habla Judith — ¿qué hacer de mi vida? — solo puede recibir una respuesta íntima, nacida del interior de uno mismo. A veces, la respuesta a esta pregunta nos viene como un fogonazo, como una revelación. En el orden intelectual, la vocación de la que hablo es un acto de fidelidad hacia uno mismo que ni se puede tematizar — no se puede encerrar en una fórmula concreta- ni pretender acallar o ignorarla como si no nos hubiese avisado.

Hay gentes que, por vocación, por una especie de tendencia natural, se inscribieron, desde la primera lectura que hicieron, a la tribu de los lectores. No eligieron su vocación de lectores, sino que fue ella —una vocación ligada a un asunto- la que los eligió a ellos. Leen, escriben, meditan. A eso lo llamo yo estudiar. Si se les pregunta «¿qué haces?», con frecuencia no sabrán responder cómo hacen lo que hacen, porque no siguen reglas fijas, pero sí un régimen de vida; tal vez digan: «Leo, luego estudio». Su forma de vida — una vida estudiosa - no es sino la respuesta que, en términos de dicha fidelidad a ellos mismos y a un pasado repleto de buenos lectores y de buenas lecturas, ofrecen a la pregunta «¿qué hacer de mi vida?», cuando esa vida está dedicada a enseñar, a transmitir y a devolver al mundo y a los otros lo que también de otros un día ellos mismos obtuvieron. Es un acto de pensamiento, de memoria y de agradecimiento.

$\mathrm{Su}$ asunto tiene que ver con algo que les tiene seducidos. Tiene que ver con una vocación que impone un régimen de existencia, una dietética y una economía de los gustos y los deseos; soportado «como una fatiga», aceptado «como una regla», seguido «como un régimen», decía Marcel Proust en relación con la tarea que la escritura de su libro parecía imponerle. Es una elección que compromete el modo como queremos escribir, en qué cuadernos hacerlo, la forma en que leemos y los libros que elegimos. Tiene que ver, sí, con esa vocación, y con una especie de amor; un amor antiguo, ancestral, en cuya historia nos hemos inscrito y que nos envuelve cuando decidimos dar el salto al torrente de la historia y del pasado.

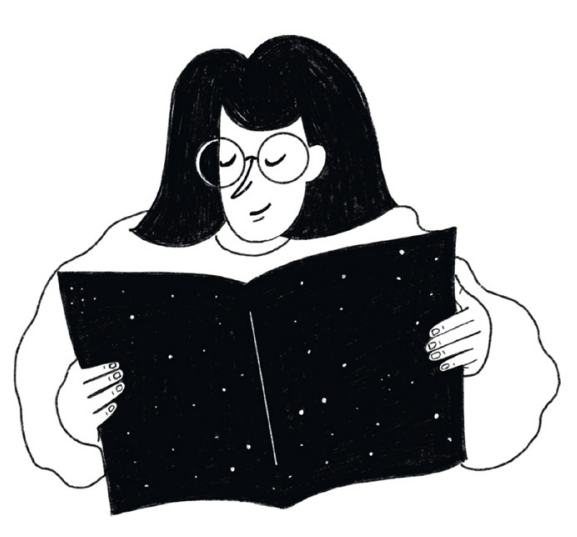




\section{"La lectura es contemplación, y supone dejar el mundo a distancia."}

Es posible llegar a percibir, en la lectura de algunas grandes obras al menos, que lo que leemos parece estar hablando de nosotros también, de lo que nos pasa en nuestro tiempo y específicas circunstancias. La lectura nos puede transformar, y cada libro es como una lente que amplía la densidad de lo real, permitiéndonos ver mejor lo que ya vivimos, pero sobre cuya importancia no habíamos reparado todavía, por no haber caído en la cuenta. Leer es la posibilidad de caer en la cuenta, un rapto del alma. En lo leído nos proyectamos y, a menudo, recreamos en nosotros lo que los héroes o heroínas de las novelas que más amamos viven o padecen. Salvo excepciones, los jóvenes de hoy no encuentran sus referentes en la buena literatura, lo que es una lástima. No se puede querer leer y pretender, al mismo tiempo, estar asegurado: es mejor no leer entonces. El lector, secuestrado por el libro, desaparece en las páginas que lee. Muchas cosas acontecen ahí. La lectura es contemplación, y supone dejar el mundo a distancia: es una inevitable ausencia de mundo y una inquieta soledad.

Podemos equivocarnos y leer mal, porque leer es traducir y porque, además, no existen dos personas con experiencias lectoras idénticas. Un mal lector, decía el poeta Auden, es como un mal traductor: es literal cuando no tiene que serlo y parafrasea allí donde debería leer literalmente. Por más que deliberadamente lo intentemos, no lograremos nada diciendo a quien lee sin gusto que lo que está acostumbrado a consumir es repulsivo - aunque hoy por hoy, tentaciones de decirlo no nos falten-, sino persuadiéndolo para que cambie de alimentación letrada. Enseñar filosofía, como enseñar a leer, es dar manjares a los otros, no porque les gusten, sino para cambiar sus gustos. No leemos para reconocernos tal y como hemos venido siendo, sino para detectar algo que todavía no somos.

El libro y la lectura son elementos centrales de la práctica del ocio estudioso y expresión de nuestra condición como seres dotados de lenguaje y razón. Por eso pedimos explicaciones al llegar a mundo, y lo que nos dan quienes ya estaban allí es un relato, una narración, una especie de cuento que nos ilumina y nos calma. Nuestro mundo capitalista es inane para los relatos, para las narraciones: cuenta (el dinero) pero no narra (lo que nos pasa). Para leer necesitamos tiempo: un tiempo libre y no producti- 
vo, necesitamos entregarnos a nuestros vicios lectores: ¿Cómo podríamos explicar la naturaleza de este vicio a quien nunca lo experimentó? La lectura cumple (o no) sus más nobles efectos, pero de ser así siempre acontece en la esfera de la singularidad de un individuo lector. Es un misterio que se den unos $\mathrm{u}$ otros efectos, los buenos y los malos. Nada está garantizado. En realidad, no obtenemos absolutamente nada de la lectura aparte de placer que nos proporciona; es algo sumamente íntimo, subjetivo, de una naturaleza inexplicable.

Leemos, escribimos y ordenamos en nuestro interior un mundo. Construimos un refugio protector, donde nos exiliamos. Todo ahí afuera parece desordenado y por momentos nos resulta amenazante. Por un tiempo, en ese muestro aislamiento parecemos a salvo. Pero sabemos que no podremos estar siempre escondidos. Debemos salir al mundo, donde el caos nos amenaza. Somos seres del mundo. ¿Qué podemos pedirle a la lectura practicada en ese territorio tan íntimo? Desde luego no la salvación del mundo; desde luego no su transformación ni la creación de un hombre nuevo. Únicamente, con algo de suerte, un poco más de lucidez y esclarecimiento, y esa clase de alimento que solo una buena lectura puede concedernos; cierto valor, quizá.

No puede pedirse al libro, ni a las prácticas lectoras, como tampoco a la tradición - a veces noble, otras infame- de una educación humanista, que siempre depositó su fe en los libros, lo que jamás podría dar: hacer que un ser humano sea moralmente bueno. El efecto que produce una buena lectura es estrictamente individual, y está en manos del azar. Ofrece cierto consuelo, cierta sensación de salvación, en un momento dado, en un espacio y en un tiempo determinados, a un lector concreto que se trasmuta, por la lectura, en lo leído.

Muchas veces he tenido la sensación, como profesor, de que lo único que podía hacer era leer en voz alta delante de mis estudiantes, compartir mi modo de leer con ellos, y esperar a que algo ocurriese, algo que les pertenecía exclusivamente a ellos: un efecto que yo no podría jamás pretender controlar a mi antojo. Pedagogía de la contaminación. Leer despacio — con ojos y dedos delicados, suaves, decía Nietzsche-, y aprender a rumiar.

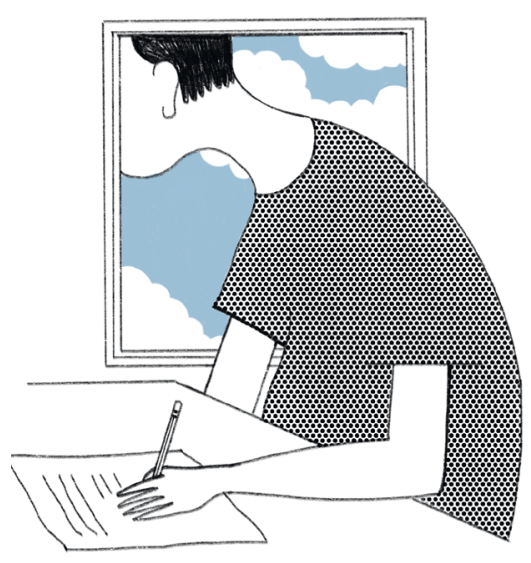




\section{"Sentarse \\ a pensar es más duro que actuar por actuar."}

Rumiar, con el pensamiento, requiere una quietud contemplativa y una fértil lentitud a la hora de reaccionar. Demanda una ociosidad intelectual más o menos desinteresada: el exercice $d u$ vide, el ejercicio del vacío.

Sentarse a pensar es más duro que actuar por actuar. Permanecer inmóviles sin morder el anzuelo y sin responder de inmediato a todas las provocaciones que un mundo como el nuestro programa para que, como salteadores de caminos, entremos al trapo de toda suerte de banalidades. Quizá no alcancemos a desentrañar en qué consiste ser un buen lector. A veces, las mejores definiciones son las que vienen del lado contrario de las cosas, de sus costados sombríos. Es mejor decir, de nuevo con Nietzsche, quiénes son los peores lectores: los que proceden como soldados que se entregan al pillaje y se apoderan de lo que puede serles útil, manchando y confundiéndolo todo, y a todos, con sus ultrajes.

Al sujeto - hombre o mujer - estudioso lo que frecuentemente le pasa es que no puede dejar de hacer lo que hace. Se siente atrapado por su objeto, seducido y algo así como hechizado. Se encierra en su gabinete de trabajo y, dentro del ámbito general de las humanidades, en ese encierro personalmente elegido se rodea de libros que lee con pasión, lo que le permite viajar en el tiempo sin moverse de su sitio. Él o ella elige los libros que lee, compone su propia biblioteca, tan arbitraria como cualquier biblioteca personal pueda llegar a ser. Elegirá leer unos libros y no otros, a autores europeos, americanos o de otro continente, y aunque circule por ahí un canon de obras imprescindibles, lo esencial para ese individuo es el hecho de estar dispuesto a aprender a discernir los libros que realmente merecen la pena ser leídos una y otra vez, vengan de donde provengan, de los que merecen dejarse definitivamente de lado. Si no lee a algunos escritores o ensayistas, conoce perfectamente los motivos de su elección, o de sus omisiones, pero no alardea de su gesto. Le basta con elegir la mejor compañía. Esos libros de su elección no son importantes porque aparezcan en un canon ya decidido por ninguna autoridad, sino que lo son porque el sujeto del que estoy hablando percibe que son interminables, porque están siempre presentes en su vida y necesita tenerlos siempre al alcance de la mano. Son libros, como los lla- 
maba María Zambrano, y mi amigo Joan-Carles Mèlich recuerda en su hermoso ensayo La sabiduría de lo incierto, «venerables». Se trata de textos que, con independencia de lo que pensemos acerca de lo que sus autores dicen en ellos, merecen cierto respeto, una actitud noble frente a ellos, cierta clase de dignidad, y desde luego una actitud, por parte de lector, de suma modestia, en vez de arrogancia. No se los venera como a dioses, porque no lo son. Se los aprecia, se los lee y relee constantemente debido a ese tipo de importancia que un lector en concreto es capaz de constatar en ellos, y porque siente que le hacen bien, porque alimentan su alma.

Es bastante alucinante lo que pasa en nuestro mundo, donde el juego de las identidades está a flor de piel, envueltas en muchísimo narcisismo, y donde es facilísimo que las más interesantes conversaciones queden abortadas antes de haber comenzado, porque siempre hay alguien en ellas al que todo le molesta o que quiere llevar la voz cantante. Cuando ya nadie lea en la casa del estudio - la escuela, la universidad - cuando el desprecio por la palabra y la grandeza del lenguaje se generalice y como un cáncer asesine a un alma potencialmente lectora, ¿dónde irán a parar esos libros que un día leímos y que al volver una vez y otra sobre ellos nos dieron la increíble sensación de estar vivos? ¿Qué se le puede decir a un joven, que se empeña en mantenerse en su arrogante ignorancia, que te dice que proponerle la lectura de un clásico es un abuso de poder por parte de su profesor y un gesto elitista? Es mejor mirar para otro lado, quizá, y mantenernos en nuestra íntima vocación. Y aunque sea como voz que clama en el desierto, insistir una y otra vez en el mensaje, disponiéndolo como una invitación: toma (el libro) lee, a ver qué pasa.

Un día alguien vivía y otro ya no, se fue. Dejó una inmensa desolación en un alma compañera y amante, con una tristeza inaudita y monumental. Pero esa otra alma, ligada todavía a la vida, recuerda. Recuerda los cuentos y las historias inventadas para que la amada pudiera pasar el trago. Recuerda ese cuento de Isak Dinesen o ese otro de Oscar Wilde que un día recitaron juntos. Recuerda ese poema que un día leyeron, un poema que tenía principio y fin, pero que permanecerá en la conciencia del superviviente eternamente, y que nadie, na-

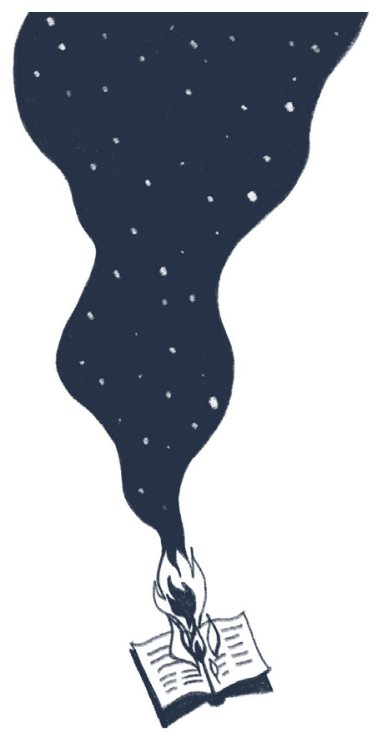




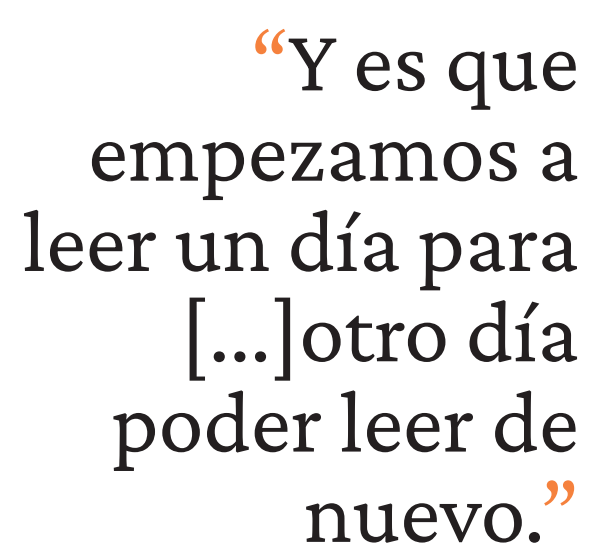

"Y es que nuevo. die y nada, podrá jamás destruir. Y es que empezamos a leer un día para — sin haberlo previsto, ignorantes del todo de lo que se nos venía encima - otro día poder leer de nuevo, con ojos y dedos delicados; y haciéndolo despacio, como esa lentitud que sobrecoge, en el amor que procuran y se regalan, a quienes mucho, en verdad muchísimo, lograron amarse, más allá de este tiempo, más allá de este ahora, más allá, tal vez, de este mundo, en el corazón de una historia única.

\section{REFERENCIAS}

Mèlich, J-C. (2019) La sabiduría de lo incierto. Lectura y condición humana. Barcelona, Tusquets.

Quignard, P. (2008) El lector. Madrid. Cuatro ediciones.

Schlanger, J. (1997) La vocation. París, Seuil. 